\title{
ABORDAGEM ODONTOLÓGICA DO PACIENTE IDOSO DIABÉTICO
}

Ana Karina MARCONDES, Jessica Gazel BONILLA, Luciane KARSTEN, Carolina Covolan MALBURG, Theresinha PASTRE

Com o envelhecimento populacional temos um aumento da prevalência de doenças crônicas e incapacitantes e uma mudança na saúde pública. As doenças no idoso geralmente não admitem cura e, se não forem tratadas, tendem a apresentar complicações e seqüelas que comprometem a independência e a autonomia do paciente (RAMOS, 2003). O Diabetes Mellitus é uma doença crônica caracterizada pela perda absoluta ou relativa de insulina, que resulta em elevados níveis de glicose no sangue (NEVILLE, 1995; SILVERMAN, 2004). A estimativa é que existam 177 milhões de portadores de diabetes no mundo e no Brasil, 17 milhões. (GEORG, 2005). Alterações fisiológicas diminuem a capacidade imunológica e a resposta inflamatória desses pacientes (CARBONI e REPPETTO, 2007). Principais manifestações bucais dos pacientes com diabetes são: xerostomia, glossodinia, ardor na língua, eritema, distúrbios de deglutição, cárie e doenças periodontais (SOUSA, 2003). O Cirurgião Dentista deve estar atento aos cuidados iniciais e preventivos e entrar em contato com o médico do paciente para certificar-se de que está compensado (CARVALHO, 2000; RANALI, 2002). Ao atendermos o idoso diabético somos responsáveis por sua saúde como um todo, não apenas bucal (PINELLI, 2005). O Objetivo desta revisão de literatura é mostrar abordagem odontológica do paciente idoso diabético. 